\title{
Advance healthcare directives
}

\author{
Sir Raymond Hoffenberg
}

Dying was once a relatively straightforward affair. If you had a terminal illness or were mortally injured, there was little your doctor could do apart from relieve your suffering and comfort your relatives. Nature would take its inexorable course. Two things changed this simple process: first, the arrival of lifesupporting or life-extending measures, for example cardiopulmonary resuscitation, artificial ventilation, hydration and nutrition. These measures, however, introduced a new set of problems: when should they be used? Once started, if and when could they reasonably be withdrawn? The second fundamental change was expansion of the human rights movement to embrace a demand for more patient autonomy in medical decision-making, with questioning and subsequent loss of medical authority. Patients wished to have more say about which medical treatment they did or did not want. As an outcome of this movement it is now almost universally agreed that mentally competent patients have an absolute right to accept or refuse any treatment offered to them. This applies even to end-of-life decisions in which patients, knowing that this may lead to their death, have the right to refuse any or all lifesustaining or life-extending measures. This right also covers mentally incompetent patients who have previously expressed their wishes in the form of an advance directive $(\mathrm{AD})$.

\section{What is an advance directive?}

An advance directive is a document, often referred to as a 'living will', written by a mentally competent adult in which they state generally or specifically all wishes regarding future medical decisions. The $\mathrm{AD}$ comes into effect in the event of that person becoming 'incompetent', when they are unable to formulate or communicate their wishes. In the $\mathrm{UK}$, a valid $\mathrm{AD}$ is legally binding under common law; it is likely to be made statutory through the Mental Capacity Act 2005 now before Parliament. To be valid, it must be written while the mentally competent adult is able to comprehend the issues, consider them rationally and express their opinion clearly (medical confirmation of mental state may be necessary). There should be no evidence of coercion or pressure. A Health Care proxy may be nominated - someone who knows and can communicate a patient's wishes if they are no longer competent to do so. A proxy does not have the right to make decisions on the patient's behalf and neither do the patient's relatives. Their role is simply to inform. A completed $\mathrm{AD}$ should be revised at regular intervals to confirm that there has been no change of mind or circumstances. It can, of course, be revoked at any time.

\section{The limitations of advance directives}

The complex interrelationship between the law pertaining to ADs, human rights, best interests and clinical judgement forms the basis of the Samantas' paper which features in this issue. ${ }^{1}$ Both authors have a legal background and the paper concentrates on the legal validity of ADs in different circumstances.

An $\mathrm{AD}$ gives the patient an absolute right to refuse or accept treatment offered to them without the need for explanation, but does not allow them to demand active steps to end their life - it is not, therefore, an easy path to voluntary euthanasia.

As the authors point out, controversy still remains about a patient's right, made either while competent or through the medium of an $\mathrm{AD}$, to demand treatment that has not been offered or is not deemed clinically appropriate. This issue came to the fore in the UK in the recent case of Burke, cited by the Samantas. A patient with progressive neurological degeneration, Burke insisted on the provision of full life-sustaining measures until natural death occurred. An original judgement, based on respect for human rights, supported his request. The possible consequences of this alarmed doctors and their professional bodies, but their concerns abated when it was overturned on appeal. Burke's wishes were made while he was alive and mentally competent; the courts have yet to consider a situation in which an incompetent patient might have made the same request in an $\mathrm{AD}$ written while competent. It is unlikely that an $\mathrm{AD}$ requesting life-prolonging measures would carry the same force as one refusing treatment.

This issue and the position of incompetent patients who have not expressed their views in an $\mathrm{AD}$ are discussed in detail by the Samantas. In the latter case, the concept of acting in the patient's 'best interests' is introduced, the legal consideration of which explores social and moral aspects as well as the
Sir Raymond Hoffenberg KBE FRCP FFPM, former President, Royal College of Physicians 
narrower medical interests. Where doubt or disagreement exists it is prudent to seek the judgement of the courts rather than rely on a pure medical appraisal.

\section{Advance directives in Britain and Australia}

Many countries and states have adopted ADs which vary in form and have varying degrees of legal standing. The Samantas present the situation as it is in Britain, but point out that this is set to change. The Mental Capacity Act of 2005, expected to be enforced in 2007, will provide a statutory framework for the law in relation to ADs and 'best interests'. The most significant proposal provides for lasting powers of attorney (LPAs) to be invested in a person who will have the power to make decisions on behalf of an incompetent person, possibly extending to personal welfare including health. This should clarify some of the ambiguities and doubts in current practice.

In Australia, different states have different laws; some have no specific legislation to deal with ADs. It would be helpful if uniformity could be achieved to facilitate cross-boundary acceptability. Queensland has one of the best models. It provides two relevant documents: an Advance Health Directive concentrates on your wishes in the event of a terminal, incurable or irreversible condition including persistent vegetative state and permanent unconsciousness. It allows an expression of your general wishes, for instance, to limit treatment to measures that maintain your dignity and comfort or to refrain from any treatment that might impede natural dying. In addition, it asks specific questions for each serious condition - do you or do you not want cardiopulmonary resuscitation, mechanical ventilation, artificial nutrition or antibiotics? This form may be used in conjunction with a second form through which you may appoint one or more persons with an Enduring Power of Attorney to act on your behalf should you lose the capacity to act for yourself. This power may cover personal health and/or financial matters.

The Queensland document has excellent accompanying explanatory notes. It advises careful thought about the sort of quality of life you would find acceptable if treatment could prolong life; how important is it to you to be able to communicate with family and friends? How much do you know about what modern technology has to offer? Discussion with a doctor, family members or close friends is recommended before completing the form.

\section{Do advance directives work?}

Many people would not wish to be kept alive once their condition had become hopeless and they had become dependent on life support. Yet very few state this in an advance directive. At one time I made it a practice to ask succeeding medical classes if any of them had signed an AD or some equivalent document; I never found a single student who had. This was perhaps understandable, for they were young and the thought of death or an incapacitating disease or injury was not foremost in their minds. When I asked what they would like to do if they were involved in an accident that left them paraplegic or otherwise wholly depen- dent on life support, a number of hands would go up in favour of having an $\mathrm{AD}$ that placed limitations on the treatment they received. Friends of mine (of an older age group) often say they would not like extraordinary measures to be applied if they were in a similar hopeless condition, yet very few translate their words into action by completing an AD. Most have no idea where to find a form or what to do with it. The result is that only a small minority of those admitted to hospital have clearly expressed what they do or do not wish to have done in the event of their becoming dependent on life support. A suggestion that competent elderly hospital patients should be given $\mathrm{AD}$ forms on admission to indicate their preferences is generally rejected on the grounds that it might constitute a form of pressure on them to select refusal of treatment options.

Studies show that failure to implement a person's wishes is not only due to the lack of a formal AD or similar document. The hospital may not have been told that a form exists, the onus being on the patient or proxy to inform them. Many hospitals specifically ask you to bring a certified copy of your AD on admission. Occasionally an AD may not be honoured because it is invalid, for example it is unsigned or there is doubt about mental capacity at the time it was drawn up, or it lacks specificity, for instance you might request that it comes into force if you are permanently unconscious, not for any other reason. I have heard of cases where the attending doctor decided to ignore a valid document, subordinating it to what he feels is his 'duty of care'. This action of imposing treatment that has specifically been refused by the patient would be regarded as illegal - a doctor who gives a blood transfusion to a Jehovah's Witness could, for example, be sued for assault.

In the US, all completed ADs are stored in an electronic registry and made available, when required, to hospitals and health care professionals across the country 24 hours a day. ${ }^{2}$ Registrants receive a letter every year that allows them to update the stored information and confirm the $\mathrm{AD}$ has not been changed or revoked. A system like this would greatly increase the likelihood of one's wishes being effected.

\section{Ethical considerations}

Those who object to the implementation of ADs tend to confuse them with direct acts of euthanasia. In an early pamphlet, the Christian Medical Fellowship actually implied that ADs are a 'passport' to it and cite as evidence the fact that euthanasia societies strongly support the use of ADs. ${ }^{3}$ This confusion is unfortunate as there is a major distinction between the two. The right to refuse treatment of any sort is based on the ethical principle of autonomy, seldom challenged and even incorporated into medical law; in Britain, as in most countries, all forms of euthanasia are illegal. An $\mathrm{AD}$ cannot request a positive action to end life; it is limited to a refusal of certain specific treatments in certain specific circumstances. The right to refuse treatment is absolute; there is no right to demand active euthanasia.

As a rule, one person's right places an obligation on someone else to fulfil it. It stands to reason that someone who has strong religious or other convictions should not be obliged, for instance, 
to withdraw mechanical ventilation knowing it would lead to death. As with assisted dying, a conscience clause is necessary.

Objections to ADs are sometimes based on pragmatic issues, such as doubts about the reliability of the diagnosis or prognosis of those one is allowing to die - the same arguments that are raised against assisted dying. In all decisions of this sort great caution is needed to minimise clinical error, including additional clinical opinions. There remains a substantial reliance on the wishes of patients and what degree of loss of independence they are prepared to tolerate.

It is also argued that a person might have changed his or her mind in the time between preparing an $\mathrm{AD}$, while mentally competent, and becoming dependent on life support. Some people, it is suggested, may feel differently when they are well and have full mental capacity to the way they might feel later when the AD might come into force. Since by definition this does not happen until the patient is mentally incompetent, the validity of any such late change of mind must be questionable.

The ethics of withdrawing artificial nutrition and hydration (ANH) from a dying patient knowing that this will lead to death is not clearly distinct from a more deliberate positive act to end life, since in both cases the intention is the same. The legal distinction is critical and quite complex. Withdrawal is legally justified if there is clinical agreement that it is no longer of any benefit. In the case of an incompetent non-sentient patient such as Tony Bland (a longstanding sufferer of persistent vegetative state) it may be permitted on the grounds of 'best interests' or, more appropriately in his case, the absence of interests. A more difficult ethical and legal issue is that of an incompetent sentient person, in whom the withdrawal of ANH may not necessarily be interpreted as an intentional deprivation of life; a positive and deliberate act is required to constitute an unlawful deprivation of life (see Samantas' paper). An important ruling by the Court of Appeal in the Burke case emphasised that any doctor who deliberately brings to an end a competent patient's life by discontinuing ANH against the wishes of the patient would be guilty of murder.

Whereas many professional bodies strongly oppose all forms of assisted dying, there is less opposition to ADs. The British Medical Association, the Mental Health Society and the Alzheimer's Society have all issued supportive statements. The Christian Medical Foundation appears to take a less committed approach ${ }^{4}$ adducing arguments for and against but refraining from outright support or condemnation.

\section{Conclusion}

As the Samantas point out, there are many legal issues surrounding the use of ADs that have yet to be resolved. The Mental Capacity Act 2005 should clarify some of the ambiguities. What is clear is that a valid $\mathrm{AD}$ drawn up by a competent person confers an absolute right to refuse specific life-sustaining treatment in the event of becoming incompetent and dependent. Those who would wish to exercise this right should ensure that they have completed an $\mathrm{AD}$ and that its content is widely known.

\section{References}

1 Samanta A, Samanta J. Advance directives, best interests and clinical judgement: shifting sands at the end-of-life. Clin Med 2006;6:274-8.

2 US Living Will Registry. www.uslivingwillregistry.com/default.asp

3 Ferguson, A. Living wills - should we support them? Nucleus, April 1993: 16-21. www.cmf.org.uk/literature/content.asp? context=article\&id=443

4 Paul, J. Advanced directives. CMF File 19 (2002). www.cmf.org.uk/literature/content.asp? context=article\&id $=155$ 